\title{
Efficiency of Governmental Funding in Hungary
}
Authors' contribution:
A) conception and design of the study
B) acquisition of data
C) analysis and interpretation of data
D) manuscript preparation
E) obtaining funding

\author{
Erika Gulyás $^{\mathrm{A}-\mathrm{E}}$, Tamás Sterbenz ${ }^{\mathrm{B}-\mathrm{E}}$, Eszter Kovacs ${ }^{\mathrm{B}-\mathrm{C}}$ \\ University of Physical Education, Budapest, Hungary
}

ABSTRACT

This paper presents the initial results of a significant research project conducted under the IOC PhD Student Research Grant Program with the support of the Hungarian Olympic Committee. Macro- and meso-level analyses were conducted within the framework of this research to analyze the competitive position of the Hungarian elite sport policy system. In the following, an essential part of the research will be presented with the aim of modeling the efficiency of the Hungarian sport funding system as the increasingly international sporting competition forces governments to invest more money in elite sport development just so they can maintain their elite sport success as the supply of medals remains basically constant. Due to these diminishing returns to the scale of investment, an elite sporting system with an efficient structure will be key in future sporting success. Data collection was based on information gained through a general questionnaire and interviews with the main stakeholders of national sport federations and the Hungarian Olympic Committee, which is the main governing body of Hungarian high-performance sport. Data collection focused on the sixteen prioritized sport federations and the five team sports that benefited from a tax relief system. Secondary data were collected regarding the national public funding for sport, elite sport, and sport by sport since 2006, and Gracenote's database was used to analyze historical performance in the different disciplines and compare Hungarian performance with that of other countries. This research will provide information to policy makers about the competitive position of Hungary in elite sport and, in this respect, explore the critical success factors that will allow Hungary to assess how best to manage its future success in an increasingly competitive international environment.

KEYWORDS elite sport, efficiency, public funding, Hungary

\section{Introduction}

In the history of the Summer Olympic Games, Hungary has nearly always been among the top ten in the medal tables, but the country's market share ${ }^{1}$ shows a decreasing trend as several nations have started to invest large sums of money in elite sport to achieve improved performance in this area.

After the elections in 2010, significant changes took place in the Hungarian sport system. This was not only due to the fact that the sport industry as a national strategic area became a governmental priority, but also because public funding of sport had grown five- or six-fold compared to previous years (in the years before

\footnotetext{
${ }^{1}$ Market share applied as a method for measuring sport performance means a medal-based measure whereby points won are converted into a percentage score of points awarded.
} 
2010 , it was $0.2 \%$ of the total state budget; now it exceeds $1 \%$, which is standard in well-developed countries in the European Union). A unique, non-direct state funding system was introduced for the so-called spectacular team sport disciplines (football, handball, basketball, water polo, and hockey), through which substantial additional funds flowed into these sports (Table 1). Moreover, comprehensive sport facility development programs are being implemented, mainly in the fields of stadium construction and youth facilities, and the city of Budapest has submitted a bid to host the Summer Olympic Games in 2024. The sport policy system was also changed in 2010 with the removal of the previous multi-channel sport financing system and the centralization of the task related to sport governance under the Hungarian Olympic Committee.

Table 1. Direct and indirect governmental expenditures on sport in Hungary (in EUR) ${ }^{2}$

\begin{tabular}{cccc}
\hline Year & $\begin{array}{c}\text { National direct funding on } \\
\text { sport (EUR) }\end{array}$ & $\begin{array}{c}\text { National indirect funding } \\
\text { on sport (EUR) }\end{array}$ & $\begin{array}{c}\text { TOTAL national } \\
\text { expenditure on sport } \\
\text { (EUR) }\end{array}$ \\
\hline 2010 & 219616129 & $\mathbf{X}$ & 219616129 \\
2011 & 199854839 & 118029567 & 317884406 \\
2012 & 223232258 & 176123768 & 399356026 \\
2013 & 236851613 & 305135411 & 541987024 \\
2014 & 544064516 & 251541102 & 795605618 \\
\hline
\end{tabular}

Source: Csorba, 2014.

The competition is increasing in international sport, with extensive investments by different national governments. This quest of nations for elite sport success has resulted in increasing academic interest in learning how efficiency in government expenditure can be increased (De Bosscher et al., 2008a). In this respect, the aim of this study is to present how efficiency and effectiveness can be defined, how efficiency and effectiveness can be measured, and the main determinants of the efficiency and effectiveness of public spending.

First, an introduction to the conceptual framework based on the related literature will be briefly presented, followed by a profile of the data and the applied methods.

\section{Conceptual framework}

There are several factors determining a country's success in elite sport. These factors can be classified into three levels:

1. Micro-level factors, such as athletes' genetic predisposition, family support, or varied incentives;

2. Meso-level factors, such as sport policies and politics;

3. Macro-level factors, such as GDP, population, average income, political climate, or wealth.

The most recent studies have found that macro-level factors, which are out of the control of policymakers, can explain $41.6 \%$ of medal-winning success at the Olympics, which is lower than earlier findings (De Bosscher et al., 2015, p. 105). This means that the impacts of the macro-level features of countries are decreasing and other factors are becoming more important. It is not a coincidence that the volume of related literature has been growing in recent years, with a focus on the identification of the factors determining elite sport achievements and the exploration of correlations between Olympic successes and national governmental expenditures (De Bosscher et al., 2008b). Since previous studies have shown that one of the most adequate indicators of elite sport success is the amount of available funding, the Hungarian elite funding system was our main focus. The approach of the research focuses on the problem identified in a significant international

\footnotetext{
${ }^{2}$ The total sport expenditures in the table exclude the money provided by state companies to sport clubs, as it is not nationally coordinated.
} 
comparison research project called SPLISS: money may correlate with Olympic results, but this does not mean that more investment in elite sport leads to more Olympic medals. These additional resources need to be invested just to maintain the level of success, as the return of these extra investments are diminishing (De Bosscher et al., 2015, p. 369).

Before the conceptual framework is introduced, it is important to clarify some terms that will be used throughout the overview of the study. We need to differentiate between professional and elite sport, which together form high-performance sport. If we follow Hungarian Sport Law, professional athletes are those who are paid for their sporting activities by a corporate sport club with whom they are contracted as an employee. However, the definition of an elite athlete is as follows:

1. An elite athlete should be regarded as an (able-bodied) athlete, who whether as an individual, or as part of a team, is ranked in the world top 16 in his or her discipline, or in the top 12 of any equivalent continental ranking system; OR

2. An athlete who receives direct or indirect funding and/or other services via support programme funded and/or organised on a national (or regional) basis for the purpose of achieving success on at least one of the following levels: the Olympic Games; the Senior World Championships; and the Senior Continental Championships in his or her sport (European, Asian, Pan American, etc.); (De Bosscher et al., 2015, p. 62).

Referring to the definitions, our study focuses on elite sport, which is mainly financed by the public sector; in terms of long-term competitiveness, it is actually the efficiency and effectiveness of public spending that plays a crucial role. First, efficiency and effectiveness must be defined, how they can be measured must be explained, and then the main determinants of the efficiency and effectiveness of public spending need to be identified.

Environmental factors

e.g., regulatory-competitive framework, socio-economic background, climate, economic development, functioning of public administration

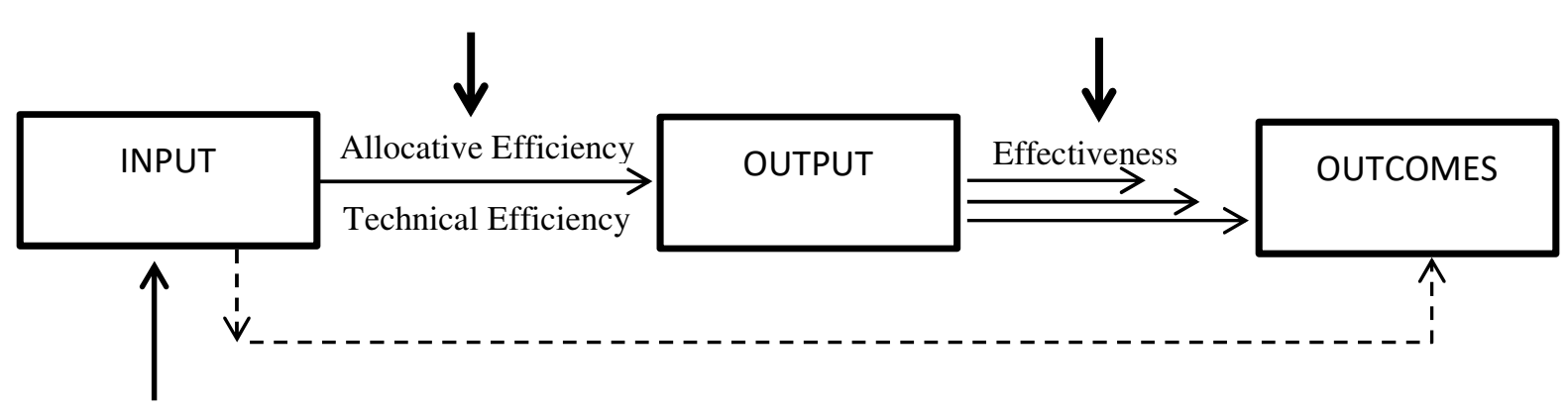

Monetary and non-monetary resources

Figure 1. Conceptual framework of efficiency and effectiveness

Source: Mandl et al., 2008, p. 3.

Effectiveness relates to the input or output required for the final objective, i.e., the outcome, to be achieved. When public spending is discussed, the outcome is often linked to welfare or growth objectives; therefore, it may be influenced by multiple factors (including outputs as well as exogenous "environmental" factors). Effectiveness is more difficult to assess than efficiency since the outcome is influenced by political choice. The distinction between output and outcome is often blurred, and output and outcome are used in an interchangeable manner even though the importance of the distinction between both concepts is recognized. For example, the outputs of an elite sport system are often measured in terms of national performance at the Olympic Games. A final outcome, however, could be an increase in national pride and a good feeling factor, or the growth of public interest in sport. Effectiveness shows the success of the resources used in achieving the set objectives. The effectiveness of a public policy can be defined as the extent to which the policies achieve 
the objectives that they are supposed to achieve (Pollitt, \& Bouckaert 2004; Mandle et al., 2008). Objectives can be described as outputs (direct results of an activity) or outcomes (wider societal aims of public policy). In the context of the current study, the objective of elite sport policy is defined as success in international competitions, which will be measured by market share (Fig. 1). We apply market share for measuring international sporting success as the use of position in the medal table, total medals won, or the points system each have one major limitation. As the number of events contested at each game has varied considerably over time, and to a lesser extent the number of points per event has also varied (for example, two or more nations "tying" for the same medal), the number of points available at each Olympic Games has also varied. In order to convert points won into a standardized measure, SIRC (2002) offers the principle of computing "market share", that is, points won as a proportion of points available to win. Using market share, it is possible to make a more accurate time series diagnosis in standardized terms.

Since 2013, the government has prioritized sixteen sport federations for considerably increased funding based on an evaluation of their past successes, coaches' performance, youth development programs, and quality of the associations. A special coaches program was introduced especially for elite coaches, providing them with a fixed monthly income from the Hungarian Olympic Committee (HOC). Due to this new funding share, the federation's budget has multiplied compared to previous years (Table 2). In our model, we will focus on these sixteen prioritized sports as the main aim, as it was in these sports that this increased funding was used to enhance national elite sport performance and secure future Olympic success.

Table 2. Amount of funding for the sixteen prioritized sports (in EUR)

\begin{tabular}{lccc}
\hline \multicolumn{1}{c}{ Sport } & $\mathbf{2 0 1 2}$ & $\mathbf{2 0 1 3}$ & $\begin{array}{c}\text { Increase in funding } \\
\text { compared to the } \\
\text { previous year (\%) }\end{array}$ \\
\hline Canoe sprint & 2226235 & 6488365 & $291 \%$ \\
Swimming & 1815081 & 6369274 & $351 \%$ \\
Fencing & 1190674 & 4082487 & $343 \%$ \\
Wrestling & 796874 & 3666174 & $460 \%$ \\
Judo & 774961 & 3341377 & $431 \%$ \\
Gymnastics & 433387 & 3272116 & $755 \%$ \\
Modern Pentathlon & 582900 & 2691952 & $462 \%$ \\
Boxing & 559094 & 2411965 & $431 \%$ \\
Athletics & 978710 & 2378155 & $243 \%$ \\
Shooting & 465194 & 1651465 & $355 \%$ \\
Skating & 467697 & 1501429 & $321 \%$ \\
Volleyball & 263306 & 1061290 & $403 \%$ \\
Tennis & 285068 & 1035090 & $363 \%$ \\
Rowing & 330261 & 842703 & $255 \%$ \\
Table tennis & 322516 & 803961 & $249 \%$ \\
Cycling & 69303 & 748194 & $1080 \%$ \\
\hline
\end{tabular}

Source: HOC.

In terms of our investigation, the well-structured central athlete development programs led by the HOC which support athletes from the age of six in reaching Olympic success (if they do so, they also receive a monthly life annuity) are also an important allocation channel in Hungary. The first stage starts for children aged 6-8 at the local level, and the following stages provide more intense and specific training possibilities for athletes aged 13-23 and scholarships for elite athletes of senior age. All athletes who reach an Olympic podium are eligible for an annuity after turning 35 years old in an amount equal to the current average Hungarian income (approximately 750 EUR per month); (Fig. 2). In recent years, about 2,500 athletes have received some kind of support for achieving sport success. These programs are coordinated by the federations, but funded by the government and HOC, who allocate the funding and monitor the programs. 


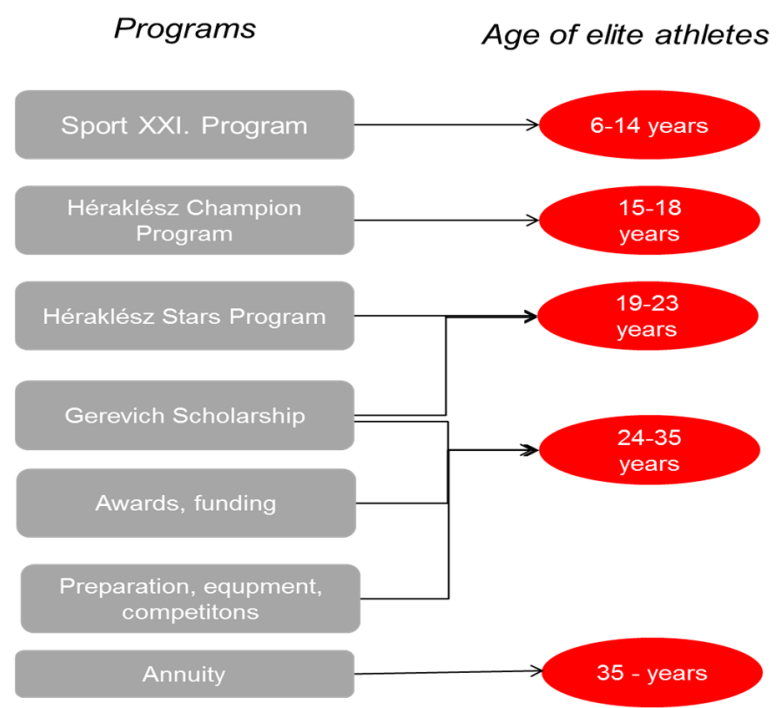

Figure 2. Hungarian athlete funding and development system

Source: http://www.nupi.hu/sportxxi/sportxxi_program

\section{Methods}

The empirical work involved a detailed questionnaire that targeted the performance directors of the sixteen prioritized sports (athletics, boxing, canoe sprint, cycling, fencing, gymnastics, judo, modern pentathlon, rowing, shooting, skating, swimming, table tennis, tennis, volleyball, wrestling) and the five team sports (basketball, football, handball, ice hockey, water polo) to follow the new structure of the governmental funding scheme. The questionnaire is structured in nine parts according to the nine pillars and contains about sixty questions. The performance directors were mainly interviewed in person. In addition, significant data collection was performed regarding the Hungarian governmental elite sport funding system and included financial data, participation data, and secondary data analysis for each sport ${ }^{3}$. The HOC provided all of the financial data.

Linear regression and cluster analysis were used for the evaluation of overall sport funding, using data gained from the performance director questionnaire and from the HOC. The relationships between the sixteen prioritized individual sports and the probable groups of sports are explored using cluster analysis. Cluster analysis is a multivariate method that aims to classify a sample of subjects (in this case, a sample of countries) into a number of different groups on the basis of a set of measured variables such that similar subjects are placed in the same group. Cluster analysis itself is not one specific algorithm, but the general task to be solved. Popular notions of clusters include groups with small distances among the cluster members, dense areas of data space, intervals, or particular statistical distributions. There are a number of different methods that can be used to carry out cluster analysis.

The clustering procedure for the analyzed sports was implemented with the hierarchical cluster method. In this case, the agglomerative method (Ward's method, based on squared Euclidean distance), in which sports start in their own separate cluster, was used. Using this method, the two "closest" (most similar) clusters are then combined, and this is done repeatedly until all of the subjects are in one cluster. At the end, the optimum number of clusters is then chosen out of all of the cluster solutions.

Using IBM SPSS Statistics software, the cluster analysis was run on a sample of analyzed sports in 2015. Variables used in the clustering procedure included:

- sum of governmental funding (HUF),

- sum of governmental funding (HUF) / number of athletes,

\footnotetext{
${ }^{3}$ We are very grateful to the Hungarian Olympic Committee for its help. We received great support in getting questionnaires back, and they also provided us with a great deal of financial data as well.
} 
- number of participants in the Heraklesz program (financial transfer for youth),

- number of medals won in the given sport.

The agglomerative process can be represented on a diagram known as a dendrogram. This diagram illustrates which clusters have been joined at each stage of the analysis and the distance between clusters at the time of joining. If there is a large jump in the distance between clusters from one stage to another, this suggests that at one stage clusters that are relatively close together were joined, whereas in the following stage the clusters that were joined were relatively far apart. This implies that the optimum number of clusters may be the number present just before that large jump in distance. The relationship between the cluster of sports and market share by sports was analyzed using the one-way ANOVA test.

We analyzed the correlation between government transfer and efficiency in the case of the sixteen analyzed prioritized individual sports with a multiple linear regression. A fitted linear regression model can be used to identify the relationship between a single predictor variable $x_{j}$ and the response variable $y$ when all of the other predictor variables in the model are "held fixed". Specifically, the interpretation of $\beta_{\mathrm{j}}$ is the expected change in $\mathrm{y}$ for a one-unit change in $\mathrm{x}_{\mathrm{j}}$ when the other covariates are held fixed.

In the first step, the linear regression with market share as a dependent variable is fitted in 2011 and 2015. Because the main question is whether the significant increase in the governmental subsidization after 2010 has had an effect on efficiency (measured by market share), the most important explanatory variables are the transfer payment and the interaction between the sum of the transfer payment and the year dummy. In the model, we use the logarithmic transformation of the transfer payment variable lagged by one year, as the financial transfer might affect the future outcome and not affect current success.

The specification of the first model is:

$\ln (\text { Market share })_{i, t}=\beta_{0}+\beta_{1} \ln (\text { Governmental funding })_{i, t-1}+\beta_{2}$ Number of participants in Heraklesz program ${ }_{i, t-4}$ $+\beta_{3}$ Year2015 $+\beta_{4} \ln (\text { Governmental funding })_{i, t-1} *$ Year2015 $+\varepsilon_{i, t}$

where $\varepsilon_{\mathrm{i}, \mathrm{t}} \sim \mathrm{N}\left(0, \sigma_{\varepsilon}^{2}\right), \ln (\text { Governmental funding })_{i, t-1_{\mathrm{t}}}$ is a logarithmic transformation of the transfer payment of sport $\mathrm{i}$ in Year $\mathrm{t}-1$, Number of participants in Heraclesz program $_{i, t-4}$ is the number of participants in a special youth support program of sport $\mathrm{i}$ in Year $\mathrm{t}-4$, and Year2015 is a dummy variable (its value is 1 if the analyzed year is 2015 ; otherwise, 0 ).

In the second model, we analyze the effect of each sport's performance on the future sum of government transfer.

The specification of the second model is:

$\ln (\text { Governmental funding })_{i, t}=\beta_{0}+\beta_{1} \ln (\text { Market share })_{i, t-1}+\beta_{2}$ Number of participants in Heraklesz program ${ }_{i, t-}$ ${ }_{4}+\beta_{3}$ Year2015 $+\varepsilon_{i, t}$

where $\varepsilon_{\mathrm{i}, \mathrm{t}} \sim \mathrm{N}\left(0, \sigma_{\varepsilon}^{2}\right)$.

Based on the two models, the causal direction between government transfer and efficiency can be identified.

\section{Results}

In the following, the results of the model examining the relationship between market share and different financial variables is analyzed.

An important result was that market share cannot be significantly explained by the amount of funding with a one-year delay (regression coefficient: 0.543 , p-values 0.270 ), or the number of athletes participating in the Heraklesz programs four years before (regression coefficient: 0.002, p-values 0.770 ), or the increased amount of funding from 2007 to 2015 (between the interaction dummy of 2015 and delayed financial funding, 
regression coefficient: 0.516 , p-values 0.807 ) based on the linear regression (Table 3). The low R-squared $(0.35)$ and insignificant variables in the model show that the analyzed factors cannot predict the market share.

Table 3. Variables in the linear regression model with the market share as a dependent variable

\begin{tabular}{lcccc}
\hline Model & \multicolumn{2}{c}{ Unstandardized } & t & Sig. \\
& Coefficients & & \\
& B & Std. & & \\
& & Error & & \\
\hline Constant & -13.920 & 8.833 & -1.576 & 0.129 \\
Ln(GovSupport_sum)t-1 & $\mathbf{0 . 5 4 3}$ & $\mathbf{0 . 4 7 9}$ & $\mathbf{1 . 1 3 2}$ & $\mathbf{0 . 2 7 0}$ \\
Year_2015 & -11.658 & 12.389 & -0.941 & 0.357 \\
Ln(GovSupport_sum)t-1*Year2015 & 0.516 & 0.640 & 0.807 & 0.429 \\
(Heraklesz_program_numofpart)t-4 & $\mathbf{0 . 0 0 2}$ & $\mathbf{0 . 0 0 7}$ & $\mathbf{0 . 2 9 6}$ & $\mathbf{0 . 7 7 0}$ \\
\hline
\end{tabular}

Source: Authors' calculation based on the data source provided by the HOC.

However, the one-year delayed market share (regression coefficient: 0.227 , p-values 0.012 ) and the fouryear delayed number of participating athletes in the Heraklész programs (regression coefficient: 0.007, pvalues 0.019) explain the amount of funding based on the liner regression equation in Table 10. We can interpret the given regression coefficients to mean that if the market share differs by one percentage and other variables in the model do not differ, the sum of government funding in the next year will differ by $0.227 \%$ on average, or, if the number of participating athletes differs by one unit and other variables in the model do not differ, the sum of government funding four years later will differ by $0.7 \%$ on average. The high-value of Rsquared (67.9\%) signifies that this model fits the data well. This relationship is clear regarding funding decisions, as it is mainly international sporting successes that are taken into account on a year-by-year basis.

Table 4. Variables in the linear regression model with the future sum of government transfer as a dependent variable.

\begin{tabular}{lcccc}
\hline \multicolumn{1}{c}{ Model } & \multicolumn{2}{c}{$\begin{array}{c}\text { Unstandardized } \\
\text { Coefficients }\end{array}$} & t & Sig. \\
& B & Std. \\
& \multicolumn{5}{c}{ Error } \\
& 19.502 & 0.426 & 45.772 & .000 \\
Constant & $\mathbf{0 . 2 2 7}$ & $\mathbf{0 . 0 8 3}$ & $\mathbf{2 . 7 3 2}$ & $\mathbf{0 . 0 1 2}$ \\
Ln(MarketShare)t-1 & 0.950 & 0.197 & 4.824 & 0.000 \\
Year_2015 & $\mathbf{0 . 0 0 7}$ & $\mathbf{0 . 0 0 3}$ & $\mathbf{2 . 5 4 2}$ & $\mathbf{0 . 0 1 9}$ \\
(Heraklesz_program_numofpart)t-4
\end{tabular}

Source: Authors' calculation based on the data source provided by the HOC.

We can conclude that market share has an effect on financial resources, but the reverse effect cannot be statistically confirmed.

By separately investigating the relationships of each of the different variables with the market share using Kendall's tau correlation-index, we find that the number of athletes who participated in the Heraklész programs shows no correlation with the market share (Table 4), but the number of athletes and coaches receiving Gerevich funding and the amount of the Gerevich scholarship has a significant, positive, and close correlation with market share (Table 5).

\section{Results of cluster analysis}

In order to explore the relationships between the sixteen analyzed prioritized individual sports and the groups of sports, a cluster analysis was applied in which the following variables were involved:

- variable 1: amount of funding,

- variable 2: amount of funding per head of registered athlete in the sport,

- variable 3: number of athletes receiving youth development services (Heraklész stars, champion).

Table 5. Correlation between Heraklész stars (t-1) and Heraklész champion (t-4) with market share 


\begin{tabular}{|c|c|c|c|c|c|c|c|}
\hline \multicolumn{4}{|c|}{ Heraklész stars } & \multicolumn{4}{|c|}{ Heraklész champion } \\
\hline Year & $\begin{array}{c}\text { Kendall's } \\
\text { tau } \\
\text { Correlation }\end{array}$ & $\begin{array}{c}\text { Sig. } \\
\text { (2-tailed) }\end{array}$ & $\mathbf{N}$ & Year & $\begin{array}{c}\text { Kendall's tau } \\
\text { Correlation }\end{array}$ & $\begin{array}{c}\text { Sig. } \\
\text { (2-tailed) }\end{array}$ & $\mathbf{N}$ \\
\hline 2007 & -0.102 & 0.616 & 16 & 2007 & - & - & - \\
\hline 2008 & 0.137 & 0.486 & 15 & 2008 & - & - & - \\
\hline 2009 & 0.176 & 0.370 & 15 & 2009 & - & - & - \\
\hline 2010 & 0.096 & 0.620 & 15 & 2010 & 0.077 & 0.691 & 15 \\
\hline 2011 & 0.174 & 0.371 & 15 & 2011 & 0.077 & 0.692 & 15 \\
\hline 2012 & 0.296 & 0.134 & 15 & 2012 & 0.008 & 0.691 & 15 \\
\hline 2013 & 0.184 & 0.345 & 15 & 2013 & 0.125 & 0.519 & 15 \\
\hline 2014 & 0.067 & 0.728 & 15 & 2014 & 0.135 & 0.487 & 15 \\
\hline 2015 & 0.145 & 0.441 & 16 & 2015 & 0.295 & 0.114 & 16 \\
\hline
\end{tabular}

Source: Authors' calculation based on the data source provided by the HOC.

Table 6. Correlation between the number of athletes and the number of coaches receiving Gerevich funding with market share

\begin{tabular}{cccc}
\hline \multicolumn{3}{c}{ Number of athletes receiving Gerevich } \\
Year & $\begin{array}{c}\text { Kendall's } \\
\text { fau } \\
\text { Correlation }\end{array}$ & $\begin{array}{c}\text { Sig. } \\
\text { (2-tailed) }\end{array}$ & N \\
\hline 2012 & 0.408 & 0.037 & 15 \\
2013 & 0.539 & 0.038 & 15 \\
2014 & 0.502 & 0.010 & 15 \\
2015 & 0.587 & 0.002 & 16 \\
\hline
\end{tabular}

\begin{tabular}{|c|c|c|c|}
\hline \multicolumn{4}{|c|}{$\begin{array}{c}\text { Number of coaches receiving Gerevich } \\
\text { funding }\end{array}$} \\
\hline Year & $\begin{array}{l}\text { Kendall's tau } \\
\text { Correlation }\end{array}$ & $\begin{array}{c}\text { Sig. } \\
\text { (2-tailed) }\end{array}$ & $\mathbf{N}$ \\
\hline 2012 & - & - & - \\
\hline 2013 & - & - & - \\
\hline 2014 & 0.794 & 0.000 & 15 \\
\hline 2015 & 0.740 & 0.000 & 16 \\
\hline
\end{tabular}

Source: Authors' calculation based on the data source provided by the HOC.

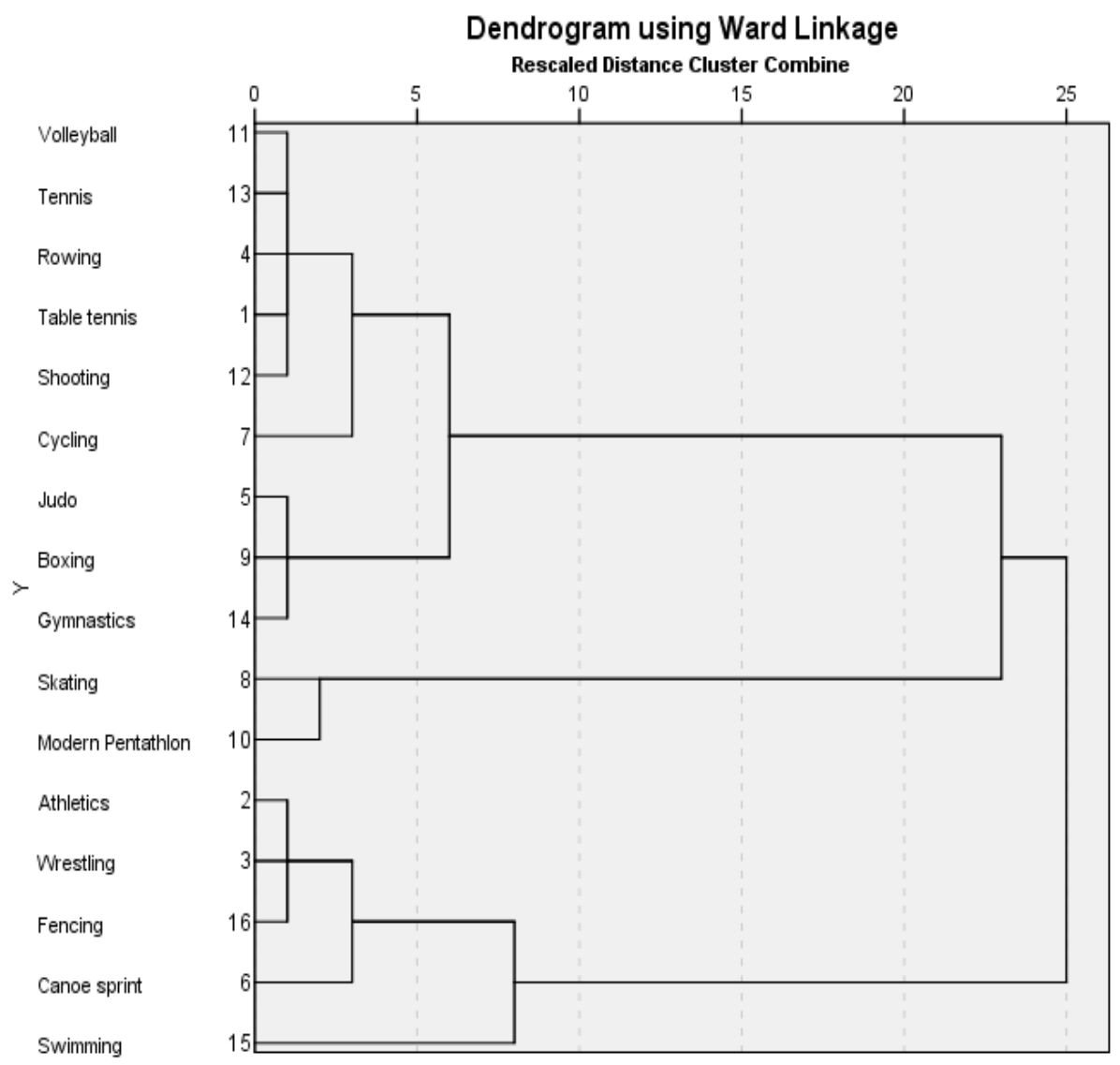

Figure 3. Dendogram of cluster analysis for 2015

Source: Authors' calculation based on the data source provided by the HOC.

Based on this cluster analysis (Fig. 3 shows the dendogram), three groups can be distinguished: 
1. Volleyball, tennis, rowing, table tennis, shooting, cycling, judo, boxing, gymnastics;

2. Skating, modern pentathlon;

3. Wrestling, athletics, fencing, canoeing, swimming.

Cluster groups differ from each other significantly based on all of the variables involved. Table 7 summarizes the characteristics of the identified groups along each variable.

Table 7. Characteristics of the identified groups.

\begin{tabular}{clll}
\hline Groups & Amount of total funding & $\begin{array}{c}\text { Amount of funding per registered } \\
\text { athlete in the sport }\end{array}$ & $\begin{array}{l}\text { Number of athletes receiving } \\
\text { youth development services } \\
\text { (Heraklész stars, champion) }\end{array}$ \\
\hline 1. & $\begin{array}{l}\text { This group gets the lowest } \\
\text { amount of total funding } \\
\text { compared to the other } \\
\text { groups. }\end{array}$ & $\begin{array}{l}\text { Members of this group have the } \\
\text { lowest amount of funding per } \\
\text { registered athlete. }\end{array}$ & $\begin{array}{l}\text { This group has the second } \\
\text { largest number of athletes } \\
\text { involved in youth } \\
\text { development programs. }\end{array}$ \\
$\begin{array}{l}\text { lowest total amount of } \\
\text { funding. } \\
\text { This group has the highest }\end{array}$ & $\begin{array}{l}\text { The sports belonging to this group } \\
\text { receive the highest amount of } \\
\text { funding per registered athlete. } \\
\text { amount of total funding. }\end{array}$ & $\begin{array}{l}\text { These sports receive the second } \\
\text { highest amount of funding per } \\
\text { registered athlete. }\end{array}$ & $\begin{array}{l}\text { number of athletes involved in } \\
\text { youth development programs. } \\
\text { This group has the largest } \\
\text { number of athletes involved in } \\
\text { youth development programs. }\end{array}$ \\
\hline
\end{tabular}

Source: Authors' study.

We also tested the relationship of the groups to the market share, and an ANOVA test showed that there is a significant relationship between the classification by clusters and the market share variable (F-test value 10.912, p-value 0.002). The first group has the lowest market share, while sports belonging to the second group have the second highest market share, and the most successful sports can be found in the third group.

\section{Conclusions}

An important result of the analysis of the effectiveness of Hungarian sport policy was the finding that market share cannot be significantly explained through the amount of funding with a one-year delay or the number of athletes participating in central youth development programs four years before, or an increased amount of funding from 2007 to 2015. The efficiency of the funding system is unclear. However, the main "test" of the new funding system will be the Rio Olympics. Regarding financial decisions, the characteristics of different sports should be taken into account and a determination of clear, written expectations for sport could help increase the efficiency of the funding system. It is recommended that professional and amateur sport be definitively separated in the case of public funding.

Sports that meet the elite sport definition in Hungary are primarily funded through the public sector and therefore cannot be characterized by market models. Sport development in commercial team sport is quite different from publicly-funded elite sport systems (De Bosscher et al., 2015, p. 51). It should be highlighted that many sports are showing explosive growth in terms of the amount of commercial resources flowing into them, which will lead to dramatic changes in national elite sport systems. We suggest that separate and sportspecific approaches are needed for the analysis of the competitiveness of commercialized professional sport, especially since national governing bodies mainly have just a regulatory role in the case of professional sport. The determinants of the competitiveness of team sports should be investigated on the level of clubs and leagues.

On the other hand, there are some basic requirements that allow an athlete or a nation to be able to enter a competition, including suitable infrastructure, coaches with strong knowledge about the given discipline, and a basic level of resources allowing athletes and coaches to conduct proper preparation and take part in competitions. 
Regarding the results of the correlation analysis (which show that there is no significant relationship between the central youth athlete development system and market share), it is suggested that these programs be harmonized with the new financial system in terms of the sports involved and the number of athletes.

This research provides an overview of the Hungarian elite sport policy system and explores the critical success factors that will allow Hungary to assess how best to manage its future success in an increasingly competitive international environment. In this respect, this study is able to inform policy makers about the competitive position of Hungary in elite sport. Moreover, this research represents the first attempt at providing a comprehensive analysis of Hungarian elite sport.

\section{REFERENCES}

Csorba, Gy.. (2014). Sportfinanszírozás /Sport financing/. Infojegyzet, 16, 1-6.

De Bosscher, V., Bingham, J., Shibli, S., van Bottenburg, M., \& De Knop, P. (2008a). A global sporting arms race: An international comparative study on sports policy factors leading to international sporting success. Aachen: Meyer \& Meyer.

De Bosscher, V., Heyndels, B., De Knop, P., van Bottenburg, M., \& Shibli, S. (2008b). The paradox of measuring success of nations in elite sport. Belgeo, 2, 217-234.

De Bosscher, V., Shibli, S., Westerbeek, H., \& van Bottenburg, M. (2015). Successful elite sport policies. An international comparison of the sport policy factors leading to international sporting success (SPLISS 2.0) in 15 nations. Aachen: Meyer \& Meyer.

Mandl, U., Dierx, A., \& Ilzkovitz, F. (2008). The effectiveness and efficiency of public spending. European Commission, Directorate General for Economic and Financial Affairs. Economic Paper 301.

Pollitt, C., \& Bouckaert, G. (2004). Public Management Reform: An International Comparison. Oxford: Oxford University Press.

AUTHOR'S ADDRESS:

Tamas Sterbenz University of Physical Education, Budapest, Hungary

Sport Economics and Decision Research Centre

Alkotás Street 44.

1123 Budapest, Hungary

E-mail: sterbenz@tf.hu

Received: 6 October 2016; Accepted: 17 November 2016 